\title{
Discussion Paper Do diagnostic delays in cancer matter?
}

\author{
RD Neal ${ }^{*, \text { I }}$ \\ 'Department of Primary Care and Public Health, North Wales Clinical School, Cardiff University, Gwenfro 5, Wrexham Technology Park,
} Wrexham LLI 3 7YP, UK

\begin{abstract}
BACKGROUND: The United Kingdom has poorer cancer outcomes than many other countries due partly to delays in diagnosing symptomatic cancer, leading to more advanced stage at diagnosis. Delays can occur at the level of patients, primary care, systems and secondary care. There is considerable potential for interventions to minimise delays and lead to earlier-stage diagnosis. METHODS: Scoping review of the published studies, with a focus on methodological issues.

RESULTS: Trial data in this area are lacking and observational studies often show no association or negative ones. This review offers methodological explanations for these counter-intuitive findings.

CONCLUSION: While diagnostic delays do matter, their importance is uncertain and must be determined through more sophisticated methods.

British Journal of Cancer (2009) I 0I, S9-SI2. doi:I0.1038/sj.bjc.6605384 www.bjcancer.com

(c) 2009 Cancer Research UK
\end{abstract}

Keywords: diagnosis; symptoms; primary care; delays

It is now well established that the United Kingdom has poorer cancer outcomes compared with much of Western Europe (Berrino et al, 2007). The consensus is that one of the major reasons for this is more advanced stage at diagnosis. One solution to this problem is to reduce diagnostic delays on the premise that this will lead to earlier stage diagnosis and improved outcomes. This paper will contextualise the diagnostic process and critically appraise the evidence that examines the association between delays and cancer outcomes.

Tumours typically grow progressively, with the 'doubling time' (a recognised period of time that it takes for the tumour to double in size) being a key measure of speed of tumour growth. This varies between types of tumour but even within tumour types, there can be significant variation, leading to unpredictable differences in patterns of symptoms and symptom complexes, speed of onset and progression of symptoms (Ford and Mitchell, 1999).

Around $90 \%$ of cancers will present symptomatically (Hamilton, 2008). There is a prevailing hypothesis within primary care that most patients have symptoms that are either self-limiting or represent chronic and benign disease until proven otherwise. In cancer this may be counter-productive, and creates a dilemma for primary care. On one hand, health professionals, whether they are general practitioners (GPs) or practice nurses (who do much chronic disease management and monitoring), have to be vigilant for 'alarm symptoms' (Jones et al, 2007) that are rarely caused by cancer. On the other hand, they are aware that most potential cancer symptoms are almost exactly the same as those of common chronic or minor diseases. Furthermore, there may be difficulty in assessing the positive predictive value of symptoms and what they really mean, and placing these within the current National Institute for Health and Clinical Excellence (NICE) urgent suspected referral guidelines (NICE, 2005). These have been shown to have a low predictive value in determining cancer (Allgar et al, 2006) and may prioritise patients who stand to gain least from urgent referral in terms of survival (Neal et al, 2007).

\footnotetext{
*Correspondence: Dr RD Neal; E-mail: nealrd@cf.ac.uk
}

Hence, the vexed question of what can be done to reduce delays is of paramount importance. The need to determine the exact relationship between symptom duration and clinical outcomes (usually survival, but sometimes stage as a proxy for survival) is essential. Delays may occur at any stage of the diagnostic cancer journey. There may be 'patient delays' where the patient may not recognise suspicious cancer symptoms or act on them. There may also be 'primary care delays', where there are unnecessary delays in the recognition, onward referral of or investigation for suspicious symptoms. After this, there may be 'system delays' where there may be a considerable wait for either non-urgent referrals (as is the case for the majority of cancer patients) or GP-initiated diagnostic investigations. Finally, 'secondary care delays' are where there may be prolonged time spent in secondary care before diagnosis, sometimes due to patients being investigated in the 'wrong' specialty.

While a small element of delay is inherently inevitable in all cancer diagnostic pathways, it is likely that in a significant percentage of patients there is considerable preventable delay. The important question is how much of this preventable delay leads to poorer outcomes. If people could be diagnosed earlier, what difference would this make to survival and other clinical outcomes?

\section{SCOPING REVIEW OF THE LITERATURE}

The existing literature in this area is very mixed and, at times, confusing. There is a dearth of trial evidence (e.g. of interventions to reduce delays). Indeed, recent systematic reviews examining factors associated with delay in colorectal and upper gastrointestinal cancers identified no trials at all (Macdonald et al, 2006; Mitchell et al, 2008). Most of the published literature reports data, inevitably, from observational studies. It may seem logical that outcomes should worsen with longer symptom duration, but there are a number of observational studies that seem to show the opposite, across a wide range of cancers. How and why should this be so? A major systematic review of the world literature on this topic is due to report in early 2010. As a prelude to this, a scoping 
Table I Summary of findings of scoping review

\begin{tabular}{|c|c|}
\hline Cancer site & Evidence ('positive' = longer delay associated with poorer outcomes, 'negative' = longer delay associated with better outcomes) \\
\hline Breast & $\begin{array}{l}\text { Systematic review: I positive study within this scoping review (Richards et al, 1999) } \\
\text { Subsequent studies: I positive (Arndt et al, 2002), I negative (Sainsbury et al, 1999) }\end{array}$ \\
\hline Lung & $\begin{array}{l}\text { Systematic review: I weakly positive study within this scoping review (Jensen et al, 200 I) } \\
5 \text { subsequent studies: } 3 \text { negative (Yoshimoto et al, 2002; Myrdal et al, 2004; Neal et al, 2007) } \\
2 \text { no association (Koyi et al, 2002; Quarterman et al, 2003) }\end{array}$ \\
\hline Colorectal & $\begin{array}{l}10 \text { no association (Robinson et al, 1984; Stubbs and Long, 1986; Kyle et al, } 1991 \text {; Majumdar et al, I999; Roncoroni et al, I999; Young et al, 2000; Kiran } \\
\text { and Glass, 2002; Gonzalez-Hermoso et al, 2004; Bharucha et al, 2005; Neal et al, 2007) } \\
4 \text { negative (Mulcahy and O'Donoghue, 1997; Langenbach et al, 2003; Olsson et al, 2004; Rupassara et al, 2006), however, for three of these, the } \\
\text { association disappears if data are corrected for emergency admissions (Mulcahy and O'Donoghue, 1997; Olsson et al, 2004; Rupassara et al, 2006) }\end{array}$ \\
\hline Melanoma & $\begin{array}{l}5 \text { no association (Krige et al, 199I; Blum et al, 1999; Oliviera et al, 1999; Brochez et al, 200।; Baade et al, 2006) } \\
\text { I weakly positive (Betti et al, 2003) }\end{array}$ \\
\hline $\begin{array}{l}\text { Upper } \\
\text { gastrointestinal }\end{array}$ & $\begin{array}{l}\text { I no association (oesophageal; Kotz et al, 2006) and } 2 \text { no association (gastric; Martin et al, I997; Porta et al, I99।) } \\
\text { I positive (oesophageal; Martin et al, 1997) and I weakly positive (oesophageal; Porta et al, |99|) }\end{array}$ \\
\hline Ovarian & $\begin{array}{l}3 \text { no association (Robinson et al, 1984; Kirwan et al, 2002; Neal et al, 2007) } \\
\text { I positive (Wikborn et al, 1996) }\end{array}$ \\
\hline Endometrial & $\begin{array}{l}\text { I negative (Crawford et al, 2002) } \\
\text { I no association (Menczer et al, 1995) }\end{array}$ \\
\hline Testicular & $\begin{array}{l}\text { I positive (Hernes et al, 1996) } \\
\text { I no association (Toklu et al, 1999) }\end{array}$ \\
\hline Bladder & 2 no association (Robinson et al, 1984; Liedberg et al, 2003) \\
\hline Prostate & I no association (Neal et al, 2007) \\
\hline Oropharyngeal & I positive (Pitchers and Martin, 2006) \\
\hline Laryngeal & I positive (Teppo et al, 2003) \\
\hline Retinoblastoma & I no association (Goddard et al, 1999) \\
\hline
\end{tabular}

review identified evidence from 47 studies in 13 different cancers; some studies reported findings for more than one cancer in a single paper (Table 1). These included two systematic reviews: one well-conducted review for breast cancer that showed a clear association between shorter symptom durations and better outcomes (Richards et al, 1999); and one less rigorous review for lung cancer that showed a weakly positive association (Jensen et al, 2001). Of the 45 other studies, 9 showed a positive association, 9 showed a negative association (i.e. shorter symptom durations were associated with worse outcomes) and 29 showed no association.

A close examination of this body of literature has identified multiple methodological issues that need to be taken into consideration when trying to determine the association between symptom duration and clinical outcomes. These will be discussed in turn.

\section{Different definitions of delays}

Different studies have used different definitions of delay, making comparison between studies and settings very difficult. Some of this is inevitable, given the different structures of international health services, including the varying roles of primary care, and the access of patients directly to secondary care specialists and diagnostic investigations. However, there seems to be some broad consensus that 'patient delay' may occur in the time period from first experience of a potential cancer symptom to telling a health professional about it. Similarly, there is broad consensus that 'primary care delay' can occur in the time period from first presentation of the symptom to onward specialist referral to GPinitiated diagnostic investigation. 'System delay' would occur in the time that it then takes for these investigations to happen, and delays in 'secondary care' happen during the time from first being seen in secondary care to diagnosis. Some papers also report 'treatment delay' - the time from diagnosis to first treatment.

\section{Different ways of measuring delays}

There are many ways of measuring delays and each has its own problems. Questions can be asked of the patient, the health professional or the medical record(s). Patient-centred studies are most likely to represent truer 'patient delays', but the answers that patients give vary enormously depending on how the questions are asked. In recent years, in-depth qualitative studies have shown that patients report symptoms attributable to their cancer for much longer than previously thought, as in, for example, lung (Corner et $a l, 2005)$ and ovarian cancers (Bankhead et al, 2005). Surveys with closed-response questions generally report much shorter delays, as is the case for data from the NHS cancer survey (Allgar and Neal, 2005). Additionally, any interview or patient-completed survey is prone to recall bias, which is hard to avoid.

Studies that use medical records to examine diagnostic delays have advantages in that records are made contemporaneously, and are not prone to recall bias. However, they are prone to missing data, which is often non-random. For example, primary care records are more likely to contain an entry for abdominal pain if the clinician thinks that the pain is significant. If they do not, the pain may not have been recorded even though it was presented. Studies using records are good at capturing events such as referrals and investigations, but doing so precisely for diagnosis can be difficult. When exactly is a diagnosis made: when a pathological specimen is reported, when the multi-disciplinary team meets, when patients are told or when a diagnosis confirmation letter is coded in primary care? This can cause difficulty and errors but there are algorithms for standardising this (Tate et al, 2009).

The significance of these difficulties is that the context for how delay is counted and captured needs to be understood. Until then, comparisons between studies may be impossible or give very conflicting results.

\section{Difficulties in comparing cancers that behave very differently}

It is difficult to make between-cancer comparisons given the variation in how they present and grow. What may hold for breast cancer may have no bearing on colorectal, lung or prostate cancer. 
Interventions aimed at reducing the duration of the diagnostic pathway are likely to be very different between different cancers and what works for one may well not work for another. However, there are some findings that may have relevance for different cancers.

\section{Difficulties in measuring outcomes}

Survival is the most important outcome. While it is the primary outcome in some parts of the literature, others use different measures as a proxy for survival. These include stage (which correlates well with survival), and different treatment options (such as eligibility for potentially curative treatments). Healthrelated quality of life measures are also of importance. The published literature reports a variety of outcome measures, and this can make comparison between studies difficult.

\section{Failure to account for speed of growth of tumours}

Tumours of a single cancer type can appear to be similar but grow at very different rates and with different levels of aggressiveness. A fast-growing tumour is likely to cause symptoms with more rapid progression, leading to a quicker diagnostic journey but worse outcomes because of aggressive growth and spread. Conversely, a slower-growing tumour is likely to cause symptoms that develop more insidiously and take longer to diagnose. However, the outcome may be better, given that curative life-prolonging treatments may be offered. Hence, there is what is sometimes called a 'paradox' (although it is really nothing of the sort) where patients with shorter delays may do worse than those with longer ones. This phenomenon has been described in several cancers, for example, endometrial (Crawford et al, 2002) and colorectal (Rupassara et al, 2006), but is likely to exist in more. It also probably explains why the negative associations reported in some colorectal cancer studies disappear when the data are corrected for emergency admissions (Stapley et al, 2006).

The issue for the body of literature looking at the association between delay and outcome is that many studies have not allowed for differences in the speed of tumour growth in their analysis. Many have simply analysed data for all patients together. It seems hardly surprising therefore that many studies have shown equivocal or negative findings.

\section{Confounding effect of lead-time bias}

Lead-time bias is the bias that may occur when outcomes are compared, but where the onset of measuring 'delay' is different as a result of diagnosis earlier in the natural history of the cancer, but

\section{REFERENCES}

Allgar V, Neal RD, Ali N, Leese B, Heywood P, Proctor G, Evans J (2006) Urgent general practitioner referrals for suspected lung, colorectal, prostate and ovarian cancer. Br J Gen Pract 56: 355-362

Allgar VL, Neal RD (2005) Delays in the diagnosis of six cancers: analysis of data from the National Survey of NHS Patients: Cancer. Br J Cancer 92: $1959-1970$

Arndt V, Sturmer T, Stegmaier C, Ziegler H, Dhom G, Brenner H (2002) Patient delay and stage of diagnosis among patients with breast cancer in Germany: a population-based study. Br J Cancer 86: 1034-1040

Baade PD, English DR, Youl PH, McPherson M, Elwood JM, Aitken JF (2006) The relationship between melanoma thickness and time to diagnosis in a large population-based study. Arch Dermatol 142: 1422 - 1427

Bankhead CR, Kehoe ST, Austoker J (2005) Symptoms associated with diagnosis of ovarian cancer: a systematic review. Br J Obstet Gynaecol 112: $857-865$

Berrino F, De Angelis R, Sant M, Rosso S, Lasota M, Coedergh JW, Santaquilani M (2007) Survival for eight major cancers and all cancers that will have no effect on the outcome. The Richards et al (1999) systematic review of breast cancer reported that only 4 out of 87 included studies took lead-time bias into account.

\section{CONCLUSION}

In conclusion, diagnostic delays in cancer do matter, but it is hard to quantify their impact on survival or mortality. The 'amount' that they matter is clear in breast cancer but far less so in other cancer types. More empirical work is needed to determine the importance of delays and, in particular, the likely effect of interventions to reduce delay in specific parts of the diagnostic journey. More work is also needed to determine the effect of delays between diagnosis and first treatment.

There are significant windows of opportunity to reduce symptom duration through:

- Reducing patient delay by increasing awareness of symptoms and the understanding of how and when to act on these.

- Reducing primary care delay by increasing awareness of potential cancer symptoms among primary care clinicians, by changing culture towards one where potential cancer symptoms are considered suspicious until proven otherwise, and by lowering the thresholds for referral or requesting GP-initiated investigations.

- Reducing system delay, by revising and implementing new urgent cancer referral guidance. These must account for the considerable body of primary care-based research on the meaning of symptoms and symptom complexes that has been published since the last update (NICE, 2005). More importantly, faster-track pathways are needed for diagnostic investigations and for patients with potential cancer symptoms that do not fulfil the urgent referral criteria. There is also a need for innovations to reduce unnecessary delay, such as proceeding straight to computerised tomography scan for a suspicious chest $\mathrm{X}$-ray, rather than referring back to the GP or directly to the chest clinic.

Working to reduce delays in cancer diagnosis in these ways will contribute to the ultimate goal of achieving earlier stage diagnosis with its associated options for curative or life-prolonging treatment.

\section{Conflict of interest}

The author declares no conflict of interest. combined for European adults diagnosed in 1995-1999: results of the EUROCARE-4 study. Lancet Oncol 8: 773-783

Betti R, Vergami R, Tolomio E, Santambrogio R, Crosti C (2003) Factors in the delay in the diagnosis of melanoma. Eur J Dermatol 13: 183-188

Bharucha S, Hughes S, Kenyon V, Anderson ID, Carlson GL, Scott NA (2005) Targets and elective colorectal cancer: outcome and symptom delay at surgical resection. Colorectal Dis 7: 169-171

Blum A, Brand CU, Ellwanger U, Schlagenhauff B, Stroebel W, Rassner G, Garbe C (1999) Awareness and early detection of cutaneous melanoma: an analysis of factors related to delay in treatment. $\mathrm{Br} J$ Dermatol 141: $783-787$

Brochez L, Verhaeghe E, Bleyen L, Naeyaert J-M (2001) Time delays and related factors in the diagnosis of cutaneous melanoma. Eur J Cancer 37: $843-848$

Corner J, Hopkinson J, Fitzsimmons D, Barclay S, Muers M (2005) Is late diagnosis of lung cancer inevitable? Interview study of patients' recollections of symptoms before diagnosis. Thorax 60: 314-319 
Crawford SC, Davis JA, Siddiqui NA, de Caestecker L, Gillis CR, Hole D, Penney G (2002) The waiting time paradox: population based retrospective study of treatment delay and survival; in women with endometrial cancer in Scotland. BMJ 325: 196

Ford MB, Mitchell MF (1999) Cancer epidemiology. In Primary Care Oncology, Boyer KL, Ford MB, Judkins AF, Levin B (eds), pp 1-27. WB Saunders: Philadelphia

Goddard AG, Kingston JE, Hungerford JL (1999) Delay in diagnosis of retinoblastoma: risk factors and treatment outcome. Br J Ophthalmol 83: $1320-1323$

Gonzalez-Hermoso F, Perez-Palma J, Marchena Gomez J, Lorenzo-Rocha N, Medina-Arana V (2004) Can early diagnosis of symptomatic colorectal cancer improve the prognosis? World J Surg 28: 716-720

Hamilton WT (2008) Introduction. In Cancer Diagnosis in Primary Care Hamilton W, Peters T (eds), pp 1-8. Elsevier: Oxford

Hernes EH, Harstad K, Fossa SD (1996) Changing incidence and delay in testicular cancer in southern Norway (1981 - 1992). Eur Urol 30: 349-357

Jensen AR, Mainz J, Overgaard J (2001) Impact of delay on diagnosis and treatment of primary lung cancer. Acta Oncol 42: 147-152

Jones R, Latinovic R, Charlton J, Gulliford M (2007) Alarm symptoms in early diagnosis of cancer in primary care: cohort study using General Practice Research Database. BMJ 334: 1040

Kiran P, Glass R (2002) Duration of symptoms and spread of colorectal cancer: a short history does not mean early disease. Ann R Coll Surg Engl 84: $381-385$

Kirwan JMJ, Herod JO, Frost O, Kingston RE (2002) Effect of delays in primary care referral on survival of women with epithelial ovarian cancer: retrospective audit. BMJ 324: $148-151$

Kotz BS, Croft S, Ferry DR (2006) Do delays between diagnosis and surgery in respectable oesophageal cancer affect survival? A study based on West Midlands cancer registration data. Br J Cancer 95: 835-840

Koyi H, Hillerdal G, Branden E (2002) Patient's and doctors' delays in the diagnosis of chest tumours. Lung Cancer 35: 53-57

Krige JE, Isaacs S, Hudson DA, King HS, Strover RM, Johnson CA (1991) Delay in the diagnosis of cutaneous malignant melanoma. Cancer 68: 2064-2068

Kyle SM, Isbister WH, Yeong ML (1991) Presentation duration of symptoms and staging of colorectal carcinoma. Aust $N Z J$ Surg 61: $137-140$

Langenbach MR, Schmidt J, Neumann J, Zirngibl H (2003) Delay in treatment of colorectal cancer: multifactorial problem. World J Surg 27: 304-308

Liedberg F, Anderson H, Månsson Å, Månsson W (2003) Diagnostic delay and prognosis in invasive bladder cancer. Scand J Urol Nephrol 37: $396-400$

Macdonald S, Macleod U, Campbell NC, Weller D, Mitchell E (2006) Systematic review of factors influencing patient and practitioner delay in diagnosis of upper gastrointestinal cancer. Br I Cancer 94: 1272-1280

Majumdar SR, Fletcher RH, Evans AT (1999) How does colorectal cancer present? Symptoms, duration, and clues to location. Am J Gastroenterol 94: $3039-3045$

Martin I, Young S, Sue-Ling H, Johnstone D (1997) Delays in the diagnosis of oesophagogastric cancer: a consecutive time series. BMJ 314: 467

Menczer J, Krissi H, Chetrit A, Gaylor J, Lerner L, Ben-Baruch G, Modan B (1995) The effect of diagnosis and treatment delay on prognostic factors and survival in endometrial carcinoma. Am J Obstet Gynaecol 173: $774-778$

Mitchell E, Macdonald S, Campbell NC, Weller D, Macleod U (2008) Influences on pre-hospital delay in the diagnosis of colorectal cancer: a systematic review. Br J Cancer 98: 60-70

Mulcahy HE, O'Donoghue DP (1997) Duration of colorectal symptoms and survival: the effect of confounding clinical and pathological variables. Eur J Cancer 33: $1461-1467$
Myrdal G, Lambe M, Hillerdal G, Lamberg K, Agustsson T, Stahle E (2004) Effect of delays on prognosis in patients with non-small cell lung cancer. Thorax 59: $45-49$

National Institute for Health and Clinical Excellence (2005) Referral Guidelines for Suspected Cancer. NICE: London

Neal RD, Allgar VL, Ali N, Leese B, Heywood PL, Proctor G, Evans J (2007) Stage, survival and delays in lung, colorectal, prostate and ovarian cancer: comparison between diagnostic routes. Br J Gen Pract 57: $212-219$

Oliviera SA, Christos PJ, Halpern AC, Fine JA, Barnhill RL, Berwick M (1999) Patient knowledge, awareness, and delay in seeking medical attention for malignant melanoma. J Clin Epidemiol 52: 1111-1116

Olsson L, Bergkvist L, Ekbom A (2004) Symptom duration vs survival in non-emergency colorectal cancer. Scand J Gastroenterol 39: 252-258

Pitchers M, Martin C (2006) Delay in referral of oropharyngeal squamous cell carcinoma to secondary care correlates with a more advanced stage at presentation, and is associated with poorer survival. $\mathrm{Br} \mathrm{J}$ Cancer 94: 955-958

Porta M, Gallen M, Malatas N, Planas J (1991) Influence of 'diagnostic delay' upon cancer survival: an analysis of five tumour sites. J Epidemiol Community Health 45: 225 - 230

Quarterman RL, McMillan A, Ratcliffe MB, Block MI (2003) Effect of preoperative delay on prognosis for patients with early stage non-small cell lung cancer. J Thorac Cardiovasc Surg 125: 108-114

Richards MA, Westcombe AM, Love SB, Littlejohn P, Ramirez AJ (1999) Influence of delay on survival in patients with breast cancer: systematic review. Lancet 353: 1119-1126

Robinson E, Mohlilever J, Zidan J, Sapir D (1984) Delay in diagnosis of cancer - possible effects on the stage and survival. Cancer 54: $1454-1460$

Roncoroni L, Pietra N, Violi V, Sarli L, Cholua O, Peracchia A (1999) Delay on the diagnosis and outcome of colorectal cancer: a prospective study. Eur J Surg Oncol 25: $173-178$

Rupassara KS, Ponnusamy S, Withanage N, Milewsky PJ (2006) A paradox explained? Patients with delayed diagnosis of symptomatic colorectal cancer have good prognosis. Colorectal Dis 8: 423-429

Sainsbury R, Johnston C, Haward R (1999) Effect on survival of delays in referral of patients with breast cancer symptoms: a retrospective analysis. Lancet 353: $1132-1135$

Stapley S, Peters TJ, Sharp D, Hamilton W (2006) The mortality of colorectal cancer in relation to the initial symptom at presentation to primary care and to the duration of symptoms: a cohort study using medical records. $\mathrm{Br}$ J Cancer 95: $1321-1325$

Stubbs RS, Long MG (1986) Symptom duration and pathologic staging of colorectal cancer. Eur J Surg Oncol 12: $127-130$

Tate AR, Martin AGR, Murray-Thomas T, Anderson SR, Cassell JA (2009) Determining the date of diagnosis - is it a simple matter? The impact of different approaches to dating diagnosis based on estimates of delayed care for ovarian cancer in UK primary care. BMC Med Res Methodol 9: 42

Teppo H, Koivunen P, Hyrynkangas K, Alho OP (2003) Diagnostic delays in laryngeal carcinoma: professional diagnostic delay is a strong independent predictor of survival. Head Neck 25: 389-394

Toklu C, Ozen H, Sahin A, Rastadoskouee M, Erdem E (1999) Factors involved in diagnostic delay of testicular cancer. Int Urol Nephrol 31: $383-388$

Wikborn C, Petterson F, Moberg PJ (1996) Delay in the diagnosis of epithelial ovarian cancer. Int J Gynecol Obstet 52: 263-267

Yoshimoto A, Tsuji H, Takazakura E, Watanabe T, Haratake J, Kasahara K, Fujimura M, Nakao S (2002) Reasons for the delays in the definitive diagnosis of lung cancer for more than one year from the recognition of abnormal chest shadows. Intern Med 41: 95-102

Young CJ, Sweeney JL, Hunter A (2000) Implications of delayed diagnosis in colorectal cancer. Aust N Z J Surg 70: 635-638 